Tunicata: Ascidia L., I767, Io87 (mentula); Botryllus Gaert., I774, 35 (schlosseri); Clavelina Savig., 1816, I74 (lepadiformis) ; Diazona Savig., I8I6, 35 (violacea); Distaplia de Valle, I88x, I4 (magnilarva); Molgula Forbes, I848, 36 (oculata). C. W. STILES,

Secretary to the International Commission on Zoological Nomenclature.

Hygienic Laboratory,

U.S. Public Health Service.

\section{Frequency Curves of Genera and Species.}

Dr. J. C. Willis and Mr. G. Udny Yule attach great importance to the fact that the form of frequency distribution for sizes of genera follows the rule that the logarithm of the number of genera plotted against the logarithm of the number of species approximates to a straight line, except that there is a marked deficiency of the larger genera (NATURE, February 9, r 922, p. 178 ).

In a recent paper (Ann. Mag. Nat. Hist. (9) xiii. p. 478) I have given my reasons for concluding that the causes that determine the sizes of genera are so many and various that an approximation to a chance effect may be expected, but with a deficiency of the larger genera, because there is no room for them in small families and because it is the systematist's business to divide them up. The object of this letter is to puint out that the series $x, x / 2, x / 3, x / 4$, etc. . . . x/x, representing the number of genera with $I, 2,3,4$, etc., species in a group where the sizes of genera are purely a matter of chance, has the property that the logarithm of the number of genera plotted to the logarithm of the number of species gives a straight line.

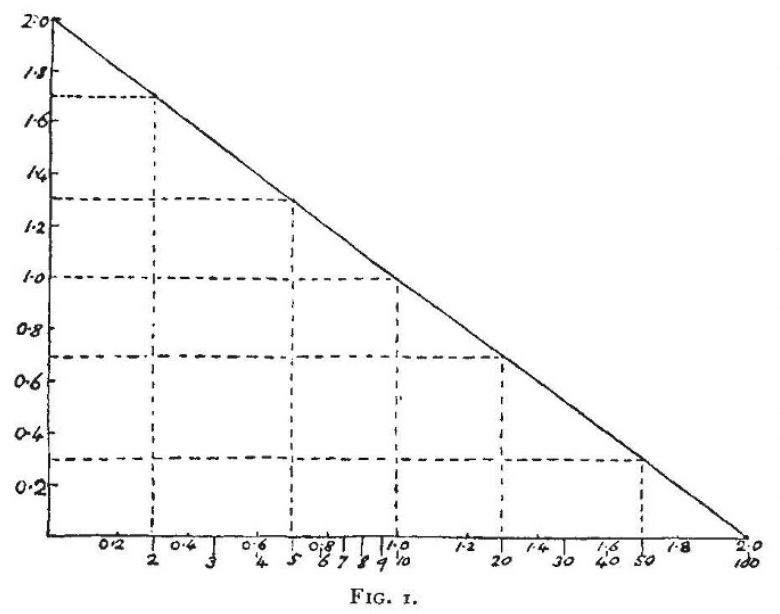

The accompanying diagram (Fig. I) shows the result of plotting the logarithms for the number of genera against those for the number of species in such a hypothetical group, having Ioo genera with I species, 50 with 2,20 with 5 , ro with ro, etc.

C. Tate Regan.

\section{Mendelism and Evolution.}

As Mr. Dover supposes (Nature, May I7, p. 712), my letter criticising some of Dr. Annandale's theoretical views was beyond my control when his untimely death was announced. I sincerely trust that my words may have given no pain when nothing was

NO. 2849 , voL. I I 3$]$ intended but the frank criticism of one working zoologist by another.

In reply to Mr. Dover, I should like to point out that his letter repeats, without any further justification, the identical assumption which $I$ criticised. He appears to be clear that he is shielding Dr. Annandale's views from the type of criticism I put forward by writing, "More than twenty years of first-hand experience of tropical biology led him to the conclusion that environment does affect certain forms of life, and that some inherited characters [sc.: "produced by environmental modification '?] at least are persistent."

Now no biologist disputes that the environment affects the individual, or that the differences seen between species, genera, etc. (in other words, their evolutionary diversities) stand in some intimate relation with their environment. (And, by the way, if $\mathrm{Mr}$. Dover will refer to the Linnean Society's Journal, vol. Xxxv., I923, p. 253 , he will find that I am not so unfamiliar as he supposes with practical research on certain aspects of ecology along just the lines he mentions. I have for long been interested in the detailed field-study of bird behaviour, and in that paper attempted to show how closely the diversity of type of courtship is correlated with differences in environment and mode of life.)

While biologists, I should say, universally accept these principles, the one question which exercises our minds is the method by which the latter or evolutionary relation between environment and characters is brought about. It is precisely here that the methodological error creeps in. To assume from field observation, however proloriged ind acute, anything whatever as to this method appears to one acquainted with the recent development of genetics as radically unsound. For without experiment it is impossible to discover not only whether modifications are inherited, but also what character-differences depend on differences in the environment, what on differences in genetic constitution. Some agreement on this point seems to me essential for progress in evolutionary biology. Correlation is not equivalent to causation.

\section{New College, Oxford,} J. S. HuXley. May 19.

\section{Refractive Index of Indiarubber.}

In NAture of May 3, p. 643, Mr. Mallock gives a list of refractive indices of various gums, including gutta percha, but not indiarubber.

The refractive index of indiarubber is of considerable importance in industry in connexion with the production of pigmented rubber goods. For example, many white powders of apparently good colour, such as magnesium carbonate, have very of their refractive index to that of rubber itself. From this fact, indeed, it is possible to derive an approximate value of the refractive index of rubber.

It is surprising, however, that no actual determination of the refractive index in question appears to be on record in scientific literature. During the preparation of a paper on the value of rubber pigments recently (Year Book of the Institution of Rubber Industry, I923, p. 295) I determined the refractive index of rubber, using a film of wellmasticated pale crepe rubber (Hevea brasiliensis) in an Abbé refractometer, and obtained a value $\mathrm{I} \cdot 525$ for $n_{1}$ at $I 5^{\circ} \mathrm{C}$. This agrees closely with the index given for gutta percha (loc. cit.), and appears to deserve recording.

Dunlop Rubber Co., Ltd.,

Fort Dunlop, Erdington, Birmingham. 